\title{
INTELECTUALIDAD Y POLÍTICA: EL CONVICTORIO DE SAN CARLOS Y BARTOLOMÉ HERRERA
}

\author{
INTELlectuality AND POLITICS: The CONVICTORIO \\ de San Carlos and Bartolome Herrera
}

\author{
José Francisco Gálvez \\ Universidad de Lima, Perú \\ https:/ / orcid.org/0000-0002-6302-9869
}

\section{Resumen}

Intelectualidad y política han sido elementos recurrentes en el manejo del poder, directa o indirectamente. El artículo pone de relevancia la influencia del Convictorio de San Carlos (Lima) en el fortalecimiento del régimen imperante. De él, presentamos a José Faustino Sánchez Carrión, liberal revolucionario, y a Bartolomé Herrera, liberal conservador, cada uno de los cuales —en su momento y contexto- tuvo el liderazgo en la política. Este hecho pone de manifiesto la importancia de los aportes de los centros de estudios en la gestión del país.

Palabras clave: historia constitucional, derecho político siglo XIX, pensamiento político.

\begin{abstract}
Intellectuality and politics have been recurrent elements in the management of power, directly or indirectly. The article highlights the influence of the Convictorio de San Carlos (Lima) in strengthening the prevailing regime. From him, we show José Faustino Sánchez Carrión, liberal revolutionary, and Bartolomé Herrera, conservative liberal, each of whom in his time and context had
\end{abstract}


the leadership in politics. A fact that highlights the importance of the contributions of the Study Centers in the management of the country.

Keywords: Constitutional history, political right nineteenth century, political thinking

\section{Introducción: la intelectualidad en la construcción del Perú}

Los albores del siglo XIX nos ilustran acerca del proceso de sustitución del sistema político correspondiente al Antiguo Régimen por uno de carácter representativo, basado en la figura del ciudadano dotado de libertad y propiedad, baluartes de los derechos naturales y condicionados a la expansión del comercio y al impacto de las guerras o procesos de ruptura. El liberalismo estableció un perfil de ciudadano (leído, próspero, con mayoría de edad e independencia económica) que hizo del sufragio un privilegio más que un derecho, supeditado al cumplimiento de dicho perfil occidental. De esta circunstancia se desprende la necesidad de contar con un pueblo involucrado en las tareas de la política, y, dentro de él, con un pequeño grupo que lo oriente, sentando las bases del vínculo de los ilustrados con la política; intelectuales cuya sapiencia y conocimiento se hallaban imbuidos en la América hispana del liberalismo católico, determinante a lo largo del siglo XVIII y presente en la opción entre mantener el virreinato o luchar por la emancipación. Esta dio lugar a un conjunto de hechos que condujeron a la guerra y al nacimiento del Estado peruano, así como a su pervivencia.

Este proceso muestra la actuación de un primer grupo de liberales, conocidos como revolucionarios, que quisieron construir una nueva sociedad a imagen de la Francia revolucionaria, bajo el discurso dogmático de los Derechos del Hombre y del Ciudadano. Posteriormente, desde 1826, hallamos un segundo grupo integrado también por liberales, pero interesados en mantener el statu quo u orden social existente. Así, se gestaron dos tendencias: moderados y, más tarde, conservadores.

Los moderados consideraban que la legitimidad provenía del consenso surgido del uso de la razón desapasionada y objetiva, a diferencia de los conservadores, quienes se inclinaban por la tradición; esta diferencia se expresó a través de sus connotados representantes, que establecieron las bases del Estado peruano. Tal representación nos permite observar el papel que cumplieron 
los diferentes intelectuales provenientes de los campos económico, social y político ${ }^{1}$, a los que Antonio Gramsci denominaba orgánicos. Su conocimiento y habilidad hizo que su labor fuese más efectiva, lo cual produjo la expansión de su clase y generó confianza ante la sociedad que les otorgaba reconocimiento como intelectuales. Sinesio López resalta esta característica al referirse al político denominado insustancial debido a que sus actos eran, en realidad, la prolongación de sus labores como abogado, sacerdote, hacendado, minero y militar, campos donde la política, aún no profesionalizada, carecía de sustancia propia al depender de las labores económicas y sociales de los titulares².

Con la aparición del sistema representativo, los intelectuales cobraron notoriedad por gozar de la información de esa mentalidad colectiva, e intentaron, a través del principio de autoridad, establecer las bases del Estado. Bartolomé Herrera no solo fue el reflejo de la intelectualidad de la época a causa de su elocuencia, sino que, además, encarnó la vida del político, que integraba la percepción humanista bajo su estilo de vida. Transmitió sus planteamientos y razonamientos a una generación, y supo forjar con convicción la defensa de la patria ante la adversidad e inestabilidad del siglo XIX.

Esto se explica también por la existencia de centros de formación donde se forjaron las élites políticas y cuya figura emblemática fue el Real Convictorio de San Carlos. Bajo el rectorado de Toribio Rodríguez de Mendoza, en él estudiaron gran parte de los primeros parlamentarios peruanos, como José Faustino Sánchez Carrión. Una segunda etapa se vivió en los años treinta con la cátedra y el posterior rectorado de Bartolomé Herrera, a quien le correspondió la difícil tarea de preparar para las siguientes décadas a la élite política intelectual y dirigente. Esta formación se vio reflejada en las clases de Filosofía Política que se impartieron en la época, disciplina que más adelante se convirtió en instrumento científico para el análisis y su planteamiento, con el fin de alcanzar el anhelado progreso: estabilidad económica, política y social.

1 Antonio Gramsci, La formación de intelectuales (México: Editorial Grijalbo, 1967), 21.

2 Sinesio López, "Intelectuales y políticos en el Perú del siglo XX», en Pensamiento político peruano (Lima: Desco, 1968), 35. 


\section{El Real Convictorio de San Carlos, cenáculo de la élite política y las manifestaciones proindependentistas}

Creado por Real Cédula del 9 de julio de 1769, el Real Convictorio de San Carlos respondió a la orientación que, desde la teoría del estatismo o regalismo, la monarquía de los Borbones había emprendido no solo para fomentar el conocimiento, sino también para comprender el contexto americano a través de la ilustración. A esto se sumaron paralelamente instituciones como la Sociedad de Amantes del País.

El convictorio absorbió en su seno al Colegio Mayor de San Felipe y San Marcos (1575), así como al Colegio Real de San Martín (1582); este último había pertenecido a la Compañía de Jesús, expulsada de los dominios hispanos en 1767.

En la enseñanza, las medidas dispuestas por Carlos III se iniciaron con la incorporación del Derecho Natural y de Gentes en los Reales Estudios de San Isidro, bajo la cátedra de Joaquín de Marín y Mendoza, quien publicó en 1776 Historia del derecho natural y de gentes, basado en las enseñanzas de Grocio, Puffendorf, Montesquieu y Johann Gottlieb Heinecke (Heinecio). De este último se publicó Elementos del derecho natural y de gentes, texto en el que se plasmaba una visión ecléctica de la Ilustración: el derecho natural comprende las leyes que han sido promulgadas por medio de la recta razón.

Estas reformas también afectaron a la Real y Pontificia Universidad de San Marcos, al aprobarse las Constituciones de 1771. En Jurisprudencia se utilizaron los Prolegómenos del derecho en general, los Elementos del derecho natural $y$ de gentes de Heinecio (para primer año); la Historia del derecho civil o de los romanos, las Instituciones de Justiniano, con explicación y notas de Heinecio (segundo año); Tratado o sintagma de las antigüedades romanas, los títulos de las Pandectas (cuarto año); Suma del derecho canónico, Historia del derecho español, público y privado, con noción de las Indias e instituciones criminales (quinto año).

En el Convictorio de San Carlos, durante el rectorado del presbítero Toribio Rodríguez de Mendoza, se llevaron a cabo las innovaciones antes aludidas, a las que se añadió la lectura del enciclopedista francés Étienne Bonnot de Condillac $^{3}$, difusor de la tesis del sensualismo, que otorgaba al alma la capacidad

3 Hugo Garavito Amézaga, «Bartolomé Herrera: ¿un liberalismo autárquico?», en Bartolomé Herrera y su tiempo, comp. Fernán Altuve-Febres Lores (Lima: Editorial Quinto Reino, 2010), 193. 
de experimentar sensaciones, las que se iban acumulando para verse reflejadas en el pensamiento, consideradas como única fuente de conocimiento.

La acogida de las lecciones de la Ilustración tuvo diferentes perspectivas. Por un lado, estaban los fidelistas, es decir, quienes se mantuvieron leales a la Corona, entre otras razones, porque, bajo una perspectiva intelectual, vieron en el Perú un conjunto de riquezas inexploradas y se convirtieron en promotores del progreso, como aquellos agrupados en la Sociedad de Amantes del País. A ellos se sumaron quienes vieron en la aplicación de dichas ideas la circunstancia propicia para mejorar el sistema político vigente, como Pedro José Chávez de la Rosa, Baltasar Jaime Martínez Compañón, Pablo de Olavide y Vicente Morales Duárez (más adelante, miembro y presidente de las Cortes de Cádiz en 1812).

Otros, en cambio, formularon críticas contra la manera en que se habían implementado las reformas. Tal fue el caso de José Baquíjano y Carrillo, quien en el acto académico de recibimiento del nuevo virrey pronunció el Elogio al virrey Agustín de Jáuregui y Aldecoa, donde sostuvo:

... que cada siglo tiene sus quimeras y sus ilusiones, desdeñadas por la posteridad, disipadas por el tiempo, y que esta luz brillante ha convencido que mejorar al hombre contra su voluntad ha sido siempre el engañoso pretexto de la tiranía, que el pueblo es un resorte, que forzado más de lo que sufre su elasticidad, revienta destrozando la mano opresora que lo oprime y sujeta ${ }^{4}$.

Estas palabras le costaron el puesto y la postergación de su carrera como juez.

Dentro de este grupo también incluimos a los liberales revolucionarios o separatistas, para quienes las ideas ilustradas referidas al ámbito económico - y luego al político- implicaban un nuevo esquema de poder que transformaba su naturaleza y daba lugar al Estado. En él, la relación soberano-súbdito se había alterado con el Despotismo Ilustrado, por lo que se había hecho necesario recuperarla a través de la soberanía, que, dentro de la teoría contractualista, reposaba en el pueblo. Así, los súbditos o vasallos pasaban a convertirse en ciudadanos o compatriotas, como lo sostendrán años después los diputados del Congreso Constituyente peruano de 1822.

4 José Baquíjano y Carrillo, «Elogio al excelentísimo señor don Agustín de Jáuregui y Aldecoa...», Boletín del Museo Bolivariano 12 (1929), 518. 
De manera paralela a la formación del Real Convictorio de San Carlos se alzaban voces contrarias a las reformas, como la del revolucionario Juan Pablo Viscardo y Guzmán. Exjesuita, nacido en Pampacolca (Arequipa), plasmó su crítica en la célebre Carta a los españoles americanos, en la cual propugnaba el retorno al pactismo, donde el monarca debía su autoridad no solo a su poder, sino también a ser aceptado por el respeto de este a los fueros preexistentes a su mandato, formados por pueblos con lenguas y culturas diferentes, pero bajo su autoridad:

Hermanos y compatriotas: [...] El descubrimiento de una parte tan grande de la Tierra es y será siempre, para el género humano, el acontecimiento más memorable de sus anales. Mas para nosotros que somos sus habitantes, y para nuestros descendientes, es un objeto de la más grande importancia ${ }^{5}$.

Sobre la base de esta perspectiva histórica, Viscardo exaltó la identidad criolla apelando al vínculo continental en dos vertientes: «Lo político, es decir, la pertenencia a una colectividad que posee un gobierno propio. Lo cultural: la posesión de rasgos culturales específicos» ${ }^{6}$. Según François Xavier-Guerra, dicho planteamiento se plasmaría en un modelo político, que, en el caso americano, fue difícil, ya que la identidad se había esparcido en los diferentes territorios americanos, siendo culturalmente evidente a través de los procesos de ruptura y prefiriéndose importar los modelos de gobierno europeos. En este ámbito hay que señalar que la identidad no se desarrolló paralelamente con la creación y demarcaciones administrativas de las comunidades políticas en las que ejercían autoridad los representantes de la Corona, y esto llevó a que se generaran fuerzas superpuestas a las vigentes, provenientes de la sociedad misma. En los inicios del siglo XVIII, la crisis monárquica, aunque había generado inconformidad en el pueblo, la ciudad o la villa, no había hecho, sin embargo, que sus habitantes dejasen de considerar públicamente al rey como cabeza de las comunidades políticas.

La labor intelectual desplegada no fue sencilla, ya que, por una parte, se pretendía fortalecer el principio de autoridad proveyendo nuevos insumos para ello, pero, al mismo tiempo, se observaba que la implementación de las

5 Juan Pablo Viscardo y Guzmán, Carta a los españoles americanos (Lima: Ministerio de Educación, 1959), 10.

6 François Xavier Guerra, «Identidad e independencia», en Imaginar la Nación, eds. François Xavier Guerra y Mónica Quijada (México, 1996), 96. 
reformas borbónicas no era eficaz y que, por el contrario, estaba desencadenando protestas de carácter económico que luego devendrían en políticas.

\section{La soberanía y los derechos naturales en los intelectuales revolucionarios}

Proclamada la independencia, el Protectorado, liderado por José de San Martín y Matorras, convocó a la Sociedad Patriótica, foro de cuarenta personalidades invitadas, para discutir sobre la forma de gobierno por adoptar, protectora de la soberanía y de los derechos naturales. La discusión se resumió en las posturas de dos preclaros ideólogos: Bernardo Monteagudo, defensor de la monarquía constitucional, y José Faustino Sánchez Carrión, simpatizante de la república.

Figura preclara del liberalismo, Sánchez Carrión (Huamachuco, 1787), también conocido como «el Solitario de Sayán», era un acérrimo defensor de la forma republicana de gobierno. Egresado del Real Convictorio de San Carlos, donde se había recibido de abogado en 1817, plasmó sus argumentos de manera anónima en sus cartas, ya que no había sido convocado al foro político. Su tesis asociaba la forma de gobierno con el territorio, las costumbres y el carácter de sus pobladores, a la usanza de Montesquieu. Sostuvo que el régimen por adoptarse debía, bajo el respeto a la libertad, seguridad y propiedad, ser eficaz: «Los infinitos males que se conocen en nuestra patria no son incurables sino porque se quiere aplicarles los específicos convenientes, o porque no se toma el trabajo de buscar el origen que los produce» ${ }^{7}$.

Opositor al sistema monárquico, para Sánchez Carrión el término emancipación era sinónimo de república; y monarquía, de decadencia; tomó como referencia el modelo estadounidense para fijar las bases del Estado peruano. Hablando sobre la inadaptabilidad del gobierno monárquico en el Perú, sostuvo que los peruanos estaban acostumbrados a recibir lo que se les dé, siendo propensos a convertirse en vasallos y nunca en ciudadanos. Señaló que, aunque la monarquía fuese constitucional, nada impediría su despotismo. Citando a Montesquieu, Sánchez Carrión proclamó que toda sociedad tenía como objeto la conservación y protección de los derechos del individuo

7 Comisión del Sesquicentenario de la Independencia del Perú, Colección documental para la Independencia del Perú (Lima: Imprenta Colegio Militar Leoncio Prado, 1974, tomo I), 15. 
a través de la voluntad inalterable de las leyes, que en aquella época se consideraban infalibles. Sin embargo, debemos indicar que la formación jurídica y la enseñanza hasta mediados del siglo XIX en la Pontificia y Real Universidad de San Marcos conservaba gran parte del modelo indiano, donde primaba el casuismo ante la sistematización jurídica que prefería a la ley como primera fuente jurídica.

Sánchez Carrión enfatizaba que, aunque hubiese una constitución liberal bajo el régimen monárquico, siempre existirían elementos que predispondrían a la servidumbre de los individuos y al sometimiento de los pueblos, dados los rezagos del sistema virreinal, por lo que concluía que terminaríamos siendo vasallos. Se trataba de argumentos rebatibles, sin embargo, pues aun en el modelo republicano las autoridades elegidas, amparándose en el poder político, podían cometer excesos.

$\mathrm{Su}$ referencia a la forma de gobierno y al proceso histórico de los Estados Unidos de América lo llevó a sostener que la existencia de un gobierno central articulado y basado en los gobiernos locales sería recomendable para una realidad tan dispar como la nuestra. No consideró, sin embargo, que la conformación de los Estados de la Unión se había producido contando con la autonomía e independencia de las trece excolonias de Norteamérica, cuyos orígenes migratorios respondían a causas religiosas, económicas, así como a persecuciones de la Corona. Sánchez Carrión asemejó el proceso gradual estadounidense desde la declaración de independencia por etapas hasta su culminación como régimen político republicano y federal que alternaba en los diferentes Estados del territorio nacional. En la versión peruana, fueron los partidos de Tumbes, Lambayeque y el Cercado de la antigua intendencia de Trujillo los que declararon su emancipación antes que Lima.

Concluida esta etapa, solo quedaba redactar la Constitución para finalizar el proceso; sin embargo, la realidad no era la misma. Las trece excolonias respondieron al patrón de la participación de afuera hacia adentro, donde cada una aportaba para construir un organismo superior a ellas. En el Perú, en cambio, el sistema operaba a la inversa, ya que todo el instrumental político había sido diseñado para girar alrededor de Lima como eje político y administrativo del Estado.

Estos puntos, después, se articularon con el resto del país, una vez concluida la guerra por la emancipación. Ello no excluyó que existan las respectivas élites de poder locales o regionales, que se conservaron. Aunque el propó- 
sito de la federación también fue acabar con el despotismo provincial, dichas élites supieron recrearse de acuerdo con las expectativas políticas. Temo que la virtud cívica del ciudadano no pudo contra la realidad existente.

Sánchez Carrión estaba convencido de que la separación de poderes debía establecerse de manera diáfana, desterrando toda arbitrariedad, como cuando uno mismo es quien elabora la ley y luego la ejecuta. Había que demarcar una rigurosa limitación entre estos tres resortes, sobre todo, entre los órganos políticos: el Poder Legislativo y el Poder Ejecutivo, que se armonizaban con el Poder Judicial. Un sistema donde los diferentes segmentos del poder se protejan y fiscalicen entre sí, evitando la superioridad de alguno de ellos sobre los otros; ya que todos eran producto de la soberanía nacional. El cuerpo legislativo, en razón de su mayor cercanía al pueblo, debía manifestarse como justo y liberal. El órgano ejecutivo, dada su condición de ejecutor de las disposiciones, constituía el más proclive al exceso de poder en su misión. El aspecto judicial, como salvaguarda de las libertades del individuo frente a una autoridad fuerte, era primordial. Más aún, cuando las normas de la sociedad se relajaban, las nociones de justicia y de imparcialidad debían cumplirse de manera inflexible.

En caso contrario, socavarían el sistema y contribuirían al proceso de inestabilidad y anarquía, que finalmente se produciría en la historia nacional. De ahí la importancia del derecho como hilo conductor del acontecer de la sociedad y que contribuiría al afianzamiento de las instituciones republicanas. Pero la ley por sí sola no era capaz de proporcionar fuerza al Estado, sino que iba acompañada de la virtud, la propiedad y el honor. Sobre la base de estos presupuestos, Sánchez Carrión separaba los derechos del hombre (ingénitos por la naturaleza) de los del ciudadano (dependen de la utilidad social, sin que dejen de ser naturales, por tanto).

La igualdad era primordial para la construcción estatal, dándose la presunción legal de que todos eran iguales; sin embargo, al vincularla con el tema de la soberanía nacional, base de representación y participación, hallamos que los ciudadanos debían cumplir una serie de requisitos, generando, en consecuencia, que la población electoral fuese inferior a la de los nacionales. Para Sánchez Carrión, la articulación de la participación popular tenía su primera manifestación en la vida edil: a través del protagonismo de cada vecino surgía la representación municipal. 


\section{La soberanía y los derechos en la opción monárquica peruana}

La monarquía constitucional representó la otra opción, encarnada en Bernardo Monteagudo (Tucumán, 1787). Partidario de Jean-Jacques Rousseau, luchó en forma desmedida por la libertad señalando que no podía aceptar la dominación de una persona sobre otra; para esto se recurría a la participación de los ciudadanos, cuya convicción lograría que la independencia no fuese tomada como un mito o un fantasma sin realidad. En enero de 1812, ante la Sociedad Patriótica de Buenos Aires, rechazó la figura del triunvirato o gobierno tripartito, que, a semejanza de la fórmula del Consulado francés, representaba una solución consensuada con las otras fuerzas políticas.

Al arribar al Perú en calidad de secretario de José de San Martín, Monteagudo se había convertido en monárquico. Notó que para que su plan tuviese éxito era necesario crear un enemigo común, lo cual lo llevó a plantear medidas radicales contra los españoles residentes en el Perú. Esta actitud le otorgó la fama de hispanófobo y le costaría más adelante su expulsión del país en 1822: «Desde el 25 de Mayo de 1809 mis pensamientos y todo mi ser estaban consagrados a la revolución [...], yo tenía una parte activa en aquel negocio, porque el buen éxito es el que cambia las denominaciones» ${ }^{8}$.

Desde el periódico El Pacificador, Monteagudo sostenía: «Los enemigos mayores de América no son los españoles sino las ideas exageradas de libertad $»^{9}$. Los ciudadanos pertenecientes a un pueblo encontraban en el ejercicio de la soberanía su asidero y principio, pues era su derecho y su deber mantenerla, algo que se lograría gracias a la convicción o virtud que tuviesen. Por ello no bastaban solo la asimilación y el convencimiento de las ideas liberales, pues la marcha de la nueva sociedad únicamente se llevaría a cabo en la medida en que el pueblo estuviese ilustrado. Consideraba la ignorancia como sinónimo de marginación; pero esto podía ser subsanado mediante el fomento de la instrucción pública, con lo cual se superarían los escollos existentes hasta ese momento. Así, la educación en las leyes y en el conocimiento harían posible la conservación de los derechos y servirían de garantía a las instituciones por establecerse.

8 Bernardo Monteagudo, Memoria sobre los principios políticos que seguí en la administración del Perú y acontecimientos posteriores a mi separación (Santiago de Chile: Imprenta Nacional, 1823), 8

9 Carlos A. de la Puente, Ensayos y oraciones (Lima: Gráfica Americana S. A., 1964), 44. 
En cuanto a los elementos que contendrían todo posible exceso de poder, a esta misión se incorporaría la libertad de imprenta, que actuaría como catalizadora de las opiniones de los individuos y cumpliría, además, el papel fiscalizador contra el poder. En caso contrario, la autoridad se convertiría en tiranía y sojuzgaría al pueblo sin mayor dificultad. Este planteamiento nos muestra la flexibilidad de su teoría política, cuya variación estaba acorde con los sucesos de la época. En su opinión, los peruanos de manera progresiva tomarían conciencia - a través de las proclamas- de los principios que aportaba la independencia: «Hoy se teme conceder demasiado poder a los gobernantes $[. .$.$] , pero en mi concepto es mucho más de temer la muy poca$ obediencia de los gobernados» ${ }^{10}$.

A través de su Memoria sobre los principios politicos que seguí en la administración del Perú, y acontecimientos posteriores a mi separación, Monteagudo sostuvo que era el Perú donde estaba más radicado el espíritu de la metrópoli, dado el número de peninsulares que residían en él debido a sus propiedades y relaciones económicas, entre otras razones. Ante una notoria incompatibilidad entre las ideas democráticas y los diferentes grupos de personas de la sociedad, diferenciadas social y racialmente, era necesario, según Monteagudo, que los habitantes abrazaran la causa patriota en forma popular, colocando el odio a los españoles como punto común, retirándolos de la escena política y de todos los ámbitos, valiéndose del secuestro de bienes y de la expatriación de cientos de ellos.

Este fue su primer objetivo, su primer principio: «... para borrar hasta los vestigios de esa veneración habitual, que los hombres tributan involuntariamente a los que por mucho tiempo han estado en posesión de hacerlos desgraciados» ${ }^{11}$.

El Perú representaba una sociedad heterogénea en diferentes aspectos, dada la diversidad de grupos sociales. Por eso, pese a que los habitantes podían compartir los ideales de la misma forma que los países europeos, en la práctica las condiciones socioeconómicas eran marcadas. De ahí se derivaba el segundo principio: el ideólogo porteño era un convencido de que el gobierno del Perú debía tener matices de una monarquía constitucional, con la

10 Comisión del Sesquicentenario de la Independencia del Perú, Colección documental para la Independencia del Perú, Epistolario de José de San Martín (Lima: Imprenta Colegio Militar Leoncio Prado, 1974, tomo XIII), 243.

11 Monteagudo, Memoria, 10. 
presencia de una clase dirigente que mantendría el poder hasta que el pueblo se ilustrase.

El tercer principio se inclinaba al fomento de la instrucción pública, con una educación práctica que garantizara que cada ciudadano conociera y gozara de sus deberes y derechos, permitiéndole más adelante convertirse en funcionario público. En este sentido, su primer paso fue la creación de la Biblioteca Nacional del Perú y la introducción del método de enseñanza lancasteriano, bajo la dirección del presbiteriano Diego Thompson, quien vino de Chile y permaneció en Lima hasta 1824. Junto con la clase ilustrada existirían legisladores, quienes, a través de su gestión, fiscalizarían la marcha del Estado.

El cuarto principio sostenía que la forma de gobierno que se adoptase debía salvaguardar la libertad del individuo, la cual se hallaba plasmada en la Constitución. Con ello se limitaría el funcionamiento de los tres poderes, fomentando el desarrollo de la felicidad para que, a su vez, el Gobierno promoviera el desarrollo de la industria, del trabajo y de los talentos. Respecto de la preservación o abolición de la esclavitud, Monteagudo afirmaba que, al reflejar la esclavitud un derecho de propiedad, ello implicaba que su posterior desaparición solo se podría dar gradualmente.

En cuanto al órgano legislativo — al cual Monteagudo denominaba Cámara de Representantes - consideraba el ideólogo que dicha institución representaba la garantía de la libertad y, por otro lado, la custodia en la fiscalización del Poder Ejecutivo. La propuesta de los principios explicados quedó complementada con la formación de una élite dirigente independiente a través del establecimiento de la Orden del Sol por parte del protector del Perú, a semejanza de la Legión de Honor instituida por Napoleón Bonaparte en Francia durante el Imperio.

\section{El Romanticismo: una nueva interpretación de los derechos naturales y de la soberanía}

Ante la desmedida puesta en práctica del discurso revolucionario francés en la defensa de los derechos naturales — que incluso llegó a plantearlos en forma dogmática, descontextualizándolos de su origen-, surgió el Romanticismo en Europa. Esta corriente de pensamiento reconstituyó el contexto recurriendo a la exaltación de los sentimientos del individuo que correspondían a profundas raíces históricas, las que, a su vez, pertenecían a una cultura 
determinada; raíces que demostraban que la aplicación de los derechos se hallaba vinculada a la formación de la nación. Esta circunstancia hizo palpable la necesidad de redescubrir el pasado como condición sine qua non para el entendimiento de las relaciones presentes y, así, distinguir en él la existencia de valores tanto colectivos como individuales bajo una idiosincrasia común, a la cual concurren tradiciones, idioma, religión, y manifestaciones racionales y espontáneas, las que en cada país tuvieron expresiones y tiempos diferentes.

Para los románticos, las coyunturas nos habían llevado a apreciar en el escenario que a los procesos históricos no les bastaba el énfasis en el modelo racional; esto no implicaba negar el derecho natural, sino interpretarlo juntamente con el vínculo indisoluble existente entre la comunidad social y económica, y el individuo. De ahí que se hace evidente la encarnación del espíritu de la nacionalidad, abordándolo de forma simultánea en el desarrollo de sus aspectos político, social y jurídico, que no siempre se realizan con la misma velocidad.

En el ámbito político, podemos advertir esta explicación en la gestación de las luchas nacionales en tierras europeas occidentales, que encuentran en Napoleón Bonaparte la figura emblemática. A través de los retratos o de la narrativa, proyectó una realidad donde la exaltación de la colectividad convertía al ser humano en epónimo o benemérito de la patria. Con respecto al aspecto social, el romanticismo mostró a la burguesía como sector emergente capaz de ocupar los ámbitos que antes eran exclusivos de la nobleza, presentándose como el motor llamado a reformular las condiciones sociales y laborales, bajo la premisa de la autonomía o manifestación de la voluntad y la que con el fenómeno de la Revolución industrial absorbió para el mercado laboral la mano de obra de niños, mujeres y hombres.

En cuanto al derecho, el Romanticismo encontró en el alemán Karl von Savigny y su obra Sobre la vocación de nuestro tiempo para la legislación y la ciencia jurídica la formación de la Escuela Histórica del Derecho como respuesta al sistema legalista francés, que había reducido el estudio del derecho al llamado «imperio de la ley», sustentado en la dogmática jurídica. Los galos habían prescindido de la costumbre e invalidaron a la jurisprudencia como fuente jurídica al considerar que el juez era solo la boca de la ley. Ante ello, Savigny rescató el rol protagónico del pueblo que, a través de su espíritu (Volkgeist), demostraba que el derecho era, ante todo, la expresión de la cultura junto con otras correspondientes a diferentes ámbitos disciplinarios. Así, se hurgaba en el redescubrimiento de las instituciones de la sociedad y del Estado en su 
conjunto, bajo la premisa de construir con rigurosidad su concepto jurídico, lo que permitía combatir la visión francesa de carácter naturista y universal que hasta entonces había predominado.

Años después, con el retorno de la monarquía al poder, Francia gozó de una estabilidad política que la intelectualidad respaldó a través de los liberales doctrinarios como Benjamin Constant de Rebecque, François Guizot y Roger Collard, quienes recondujeron la teoría liberal despojándola de la característica revolucionaria y del discurso descarnado de los derechos naturales racionales. En esa misma línea, Joseph de Maistre propuso el estado de emergencia frente a la institucionalidad liberal, retomando para ello el principio de autoridad presente en la república cristiana. Desde su teología política, se opuso a la institucionalidad francesa de finales del siglo XVIII, que había declarado la abolición de las corporaciones medievales bajo la universalidad de la ley. En los hechos, la sociedad se había resistido a la injerencia del poder político que pretendía establecer la uniformidad en la imagen del hombre como ciudadano.

En opinión de Maistre, la presencia de Dios a través de una autoridad impuesta resolvería el conflicto con la unificación de la sociedad política y civil sin que esto fuese sinónimo de arbitrariedad en el poder. De la figura del soberano se desprendían tanto los derechos de la persona que eran otorgados en concesión como aquellos que estaban en concordancia con el estado de necesidad y de las cosas. La ley era superada por el ejercicio del poder político, en cuyo texto los legisladores actuarían en nombre de Dios retomando costumbres provenientes del medioevo con elementos sociales y económicos.

Otro crítico de los irrestrictos derechos naturales fue Juan Donoso Cortés, quien sostuvo que el modelo político debía regularse por la invocación de la justicia y la aplicación de la llamada «soberanía de la inteligencia». La justicia era imperativa y servía de garantía al ejercicio de los derechos proclamados y limitados. Por su parte, el concepto de soberanía rescataba de los doctrinarios liberales sus elementos formativos, como el consenso y la legitimidad, pero su ejercicio era derivado a los más capaces e ilustrados, quienes reproducían los mandatos de la voluntad divina. 


\section{El Convictorio de San Carlos y Bartolomé Herrera}

En el Perú podemos evidenciar elementos previos al arribo del Romanticismo europeo y que nos demandan vincular el manejo del poder con la idiosincrasia limeña: el autoritarismo, la identidad local, la exaltación de la cultura nacional y el surgimiento del nacionalismo frente a los proyectos políticos de carácter continental de los libertadores José de San Martín y Simón Bolívar. Estas características ponen en entredicho la afirmación vertida por José de la Riva Agüero y Osma en 1905: «Ha sido una ley de la evolución literaria peruana y en general de la América Española, andar siempre con veinte años de retraso de la europea» ${ }^{12}$. En el Perú, la proclamación de la independencia no trastocó en su totalidad la tradición hispana, lo que hizo difícil la incorporación de los elementos revolucionarios franceses en todos los ámbitos de la sociedad. Aquí contemplaremos que la partida de los libertadores fue sustituida por la aparición de caudillos imbuidos del discurso nacionalista.

En el aspecto político, el romanticismo se aunó al poder ejecutivo fuerte que, gracias al caudillismo, superó el liderazgo del Congreso nacional. Si bien fracasó la opción monárquica promovida por San Martín y Monteagudo, ello no implicó la desaparición de sectores identificados con el gobierno fuerte, cuyos elementos provenían del despotismo ilustrado: José María de Pando, Andrés Reyes, Mariano Ignacio de Vivanco, entre otros. Pando, ministro de Estado del gabinete de Fernando VII durante el Trienio Liberal (1820-1823), se percató durante su gestión de que esta forma de gobierno no había surtido efecto debido a la poca capacidad para limitar el liderazgo de ministros y militares, así como para hacer frente a las eventuales manifestaciones populares. La idea del rey como autoridad y padre sería reemplazada en la República por la del militar cuya actuación unificaba esfuerzos para la consolidación del Estado. Así, por ejemplo, aparecería la del Libertador Simón Bolívar bajo el hermoso título de «Padre y Salvador del Perú», concedido por el Congreso.

Bartolomé Herrera Vélez (Lima, 1808) fue un profeso defensor de los conservadores - los que «conservaban la Constitución»—; se formó intelectualmente en el Convictorio de San Carlos, donde más tarde se desempeñaría como catedrático y rector. Al inicio recibió el influjo de la filosofía política de

12 José de la Riva-Agüero y Osma, Carácter de la literatura del Perú independiente (Lima: Pontificia Universidad Católica del Perú, 1961), 111. 
Montesquieu y Rousseau, con las tesis dogmáticas de los derechos naturales, de las que después se apartó y reemplazó con las del Romanticismo.

La historiografía reconoce el protagonismo de Herrera a partir de la oración pronunciada en las exequias ${ }^{13}$ del expresidente Agustín Gamarra. Su contenido invitaba a la reflexión de los asistentes a analizar la situación por la cual había atravesado el país desde la independencia, cuyo punto capital consistía en la falta del principio de autoridad, que el caudillaje había resuelto a su modo. Esta opinión fue recogida por las generaciones venideras, que debatieron respecto a la conveniencia o no de la forma como se sustentaba el ejercicio de la soberanía, base del sistema representativo, y que pasaría por un cambio gradual, de liberal a democrático.

En aquellos tiempos las constituciones peruanas tenían un vaivén parecido al de las hojas con el viento del otoño: nunca se quedaban quietas, sino más bien eran volátiles debido a los tropiezos del Parlamento peruano en sus esfuerzos por fortalecer la base sociojurídica de integración, careciéndose de reglas acorde con esta. Bartolomé Herrera era consciente de que el llamado al orden no podía reposar en una persona sino en la concurrencia de voluntades; de lo contrario, las instituciones terminaban por ser nominales:

¿Hemos cooperado todos a la ventura y respetabilidad de la Nación? ¿No es verdad que hay quienes ignoran que el amor a la patria es caridad más perfecta que la particular; no saben si es virtud; y marchan ilusos a la ruina, a que su indiferencia les conduce? ¿No es verdad que este criminal abandono de nuestros deberes, como individuos de la sociedad en que vivimos y ese principio de resistencia aun a los legítimos y necesarios mandatos se ha comunicado a una parte del ejército, cuyo principio de acción, cuya vida es la obediencia? ${ }^{14}$

Esto nos confirma que la anarquía generada no era espontánea y que las lagunas existentes tanto en la realidad jurídica como en la política propiciaban regímenes efímeros, y que solo la existencia de una representatividad colectiva podía fortalecer la defensa en pro de la vigencia del Estado.

13 Bartolomé Herrera, «Oración que en las exequias celebradas el día 4 de enero de 1842 en la iglesia Catedral de Lima por el alma de S. E. el Generalísimo Presidente de la República D. Agustín Gamarra, muerto gloriosamente en el campo de Incahue, pronunció el Dr. D. Bartolomé Herrera, Cura y Vicario de Lurín», en Escritos y discursos (Lima: Librería Francesa Científica y Casa Editorial Rosay, 1929, tomo I), 29.

14 Herrera, Escritos y discursos, 29. 
En medio de este debate doctrinario, los caudillos monopolizaban la vida política del país: los generales Francisco Vidal, Manuel Ignacio de Vivanco, Rufino Torrico, Antonio Gutiérrez de la Fuente, Ramón Castilla y Domingo Nieto, quienes gracias a sus simpatizantes y adherentes lograban concentrar fuerzas para desplazar a sus respectivos contendores.

En este panorama, los talentos de Bartolomé Herrera nos permiten construir una personalidad de características invalorables, como la tenacidad y la disciplina para llevar adelante los objetivos trazados, así como su desempeño en la vida pública que le correspondió ejercer. Sus actos tuvieron como ejes el amor a la patria, su deseo de armonía y beneficio social en pro de la formación de una nación con espíritu libre pero respetuosa de los cánones del Estado de derecho.

Desde el convictorio su labor fue fecunda, convencido de que era necesaria la formación de una nueva generación de políticos: «... en breve, antes de ocho años, una generación nueva saldrá de San Carlos a cegar la fuente de lágrimas que ha inundado a la República» ${ }^{15}$. Innovó el currículo proveniente de la administración de Rodríguez de Mendoza, destacando el libro Curso de derecho natural o de filosofía del derecho de Heinrich Ahrens, el Curso de derecho público interno y externo, tratado del comendador Silvestre Pinheiro Ferreyra - traducido y comentado por el propio Herrera- ${ }^{16}$, el Curso de política constitucional y los Principios de política de Benjamin Constant de Rebecque, así como el derecho correccional, que en Francia permitió conocer la nueva dogmática aplicada al aspecto sancionador o penal ${ }^{17}$.

Las circunstancias demandaban la respuesta a la incertidumbre y a la improvisación de los cuales habían sido objeto los efímeros regímenes. La formación que recibieron los intelectuales los compulsaba a defender por sobre todas las cosas a la patria como valor superior de la sociedad, y esto solo se lograría mediante el ejercicio de los poderes del Estado y el desarrollo de las libertades que asistían la vida de la persona misma. Fue el Convictorio de San Carlos la representación ideal de su tesis de la soberanía de la inteligencia que agrupó a:

15 José Pareja Paz Soldán, Historia de las constituciones nacionales (Lima: Gráfica Zenit, 1944), 107.

16 Mario Alzamora Valdez, El pensamiento politico de Bartolomé Herrera (Lima: Mercurio Peruano 273, 1950), 213.

17 Jorge Guillermo Leguía, Hombres e ideas en el Perú (Santiago de Chile: Ediciones Ercilla, 1941), 131 . 
... Luciano y a Luis Benjamín [Cisneros], a los ilustres Gálvez — de Pedro dijo Herrera que era, conjuntamente con la Virgen de Nuestra Señora de Loreto, las dos mejores joyas del Convictorio y José fue el hombre representativo de la Asamblea Liberal del 56 - a Clemente de Althaus, a Ricardo Palma —el Príncipe de nuestras Letras y que ha recordado aquella juventud inolvidable en la Bohemia de mi Tiempo- a los poetas Adolfo García y Carlos Augusto Salaverry, a los García y García, marinos o diplomáticos, a los ilustres conservadores Toribio Pacheco, Evaristo Gómez Sánchez, José Antonio Barrenechea y Pedro José Calderón, los más fieles continuadores del pensamiento del maestro, a sacerdotes de la talla de Monseñor Sáenz o marinos como Camilo N. Carrillo ${ }^{18}$.

Desde el claustro carolino, Herrera fue desarrollando la tesis del poder ejecutivo fuerte que ya había calado en la intelectualidad limeña desde Felipe Pardo y Aliaga y era contraria para quienes impulsaban irrestrictamente la defensa de derechos. Percepción que no era ajena en la redacción de la Constitución cuando primero se hablaba del Estado y luego se enumeraban los derechos de la persona. El proyecto de Carta Magna de 1860 nos permite corroborar la tesis de la soberanía de la inteligencia, desarrollada por Maistre y secundada por Herrera, aplicada en la composición congresal bicameral, donde los miembros de la Cámara de Senadores provendrían de sectores económicos, administrativos y de la cultura.

La experiencia del Convictorio de San Carlos le sirvió para insistir en el carácter de la soberanía de la inteligencia, cuya fundamentación fue defendida en el debate referido a la ampliación del voto a los indígenas, defendido por Pedro Gálvez Egúsquiza. Para Herrera, el indio, al ser analfabeto, no podía considerársele capaz de integrar el electorado de entonces, más aún cuando esta ampliación hacía pensar en la posibilidad de la compra de sus votos; sin embargo, los pobladores andinos pagaban impuestos $\mathrm{y}$, bajo el argumento francés según el cual quien paga vota, era razonable su pretensión. La teoría de Herrera conciliaba la capacidad aludida como requisito sine qua non con la moral, la honestidad y la identidad manifestada como patriotismo. Esta exclusión no significaba dejar de reconocer el aporte de lo autóctono, como el de los incas, cuyo orden y unidad hicieron factible la empresa de evangelización y catequización, llevando el evangelio a las tierras conocidas. La tradición española, por su parte, proporcionó unidad, estabilidad y orden. De estos valores,

18 Pareja Paz Soldán, Historia, 108. 
el orden representaba el tema prioritario que deseaba plasmar en un proyecto político.

En lo académico, Bartolomé Herrera, rector del Real Convictorio de San Carlos en 1848, expresó una posición sumamente valiosa para la época al introducir nuevos planteamientos en torno a la vinculación entre el derecho público y el derecho de gentes, desarrollando la tesis dualista de ambos, y a los que él llamó interno y externo, en referencia al ámbito y a la producción del Estado peruano.

$\mathrm{Al}$ año siguiente, fue elegido diputado por el departamento de Lima por dos años, y presidió su cámara durante dicho periodo. Le correspondió a su gestión abordar los temas neurálgicos, como la elección de los obispos dentro de la relación Iglesia-Estado peruano, en momentos en los cuales se buscaba un acercamiento político con la Santa Sede para efectos del reconocimiento de la independencia peruana; pero, por otro lado, el ejercicio del derecho de patronato nacional, según el cual el presidente de la República podía nombrar a los obispos. Otro tema de coyuntura fue la ampliación del sufragio a los indígenas, uno de los temas que más debatió con Pedro Gálvez Egúsquiza, su exalumno.

Estas discusiones pusieron de manifiesto en el recinto parlamentario las llamadas tesis herreristas, basadas en:

a) La teoría escolástica. Se interpreta que Dios es el centro del poder y el único que lo puede emitir; lo transfiere al pueblo, al cual se considera el depositario de la autoridad, y es este, en consecuencia, el origen de la transmisión de la energía social al soberano, sea rey o presidente. Este debe ser intelectualmente el más adecuado representante de la sociedad para ejercer el poder en nombre de Dios por medio de las leyes del derecho natural y buscar como único objetivo la satisfacción del bien común para la felicidad de sus nacionales.

La idoneidad en el ejercicio de los cargos representativos implica que estos deben quedar reservados para aquellos cuya inteligencia y cualidades denoten el perfil del parlamentario, absteniéndose quienes no tuviesen dicha correspondencia, y menos los que se encuentren en prácticas consideradas corruptas. En un principio, Herrera sometió su planteamiento a la presunción de la buena fe para las designaciones o nombramientos de los candidatos provenientes de la antigua nobleza colonial, culta y educada. Sin embargo, esto 
tropezaba con la poca identificación existente con el naciente Estado, cuyos políticos mostraban una actitud que se debatía entre el divorcio de la realidad nacional y la apatía, por lo que Herrera dirigió su labor a la formación de una élite política compuesta por jóvenes que eran reclutados a través del Convictorio de San Carlos para luego convertirlos en líderes conciliadores y no desintegradores.

b) El proyecto de Constitución corporativa. El Poder Ejecutivo se vería fortalecido bajo una unidad de acción, acompañado de principios que fomenten el orden, sustentado en el corporativismo. En segundo lugar, la pervivencia del sistema bicameral, donde el Senado asumía funciones corporativas y no solo políticas, y cuyo origen sería selectivo.

Se retomaba de la Constitución de 1828 el Consejo de Gobierno como órgano de apoyo a la gestión presidencial. El proyecto ponía de nuevo en debate la vieja discusión en aras de lograr la anhelada estabilidad política mediante formas de articulación y control entre los poderes políticos donde el liderazgo del Poder Ejecutivo se vería fortalecido y acompañado de una cámara funcional. Fruto de dicha discusión fue el rescate de los mecanismos de fiscalización plasmados en la Carta Magna de 1856.

La tesis del llamado senado funcional herreriano pervivirá hasta la Constitución de 1933, pues fue abolido en el plebiscito convocado por el general Óscar R. Benavides tres años después, con lo cual la elección de senadores se llevó a cabo, desde entonces, como la de diputados. Herrera era un convencido de que debería convocarse a los miembros de la sociedad peruana que tuvieran madurez y experiencia en lides políticas para que integren el Senado — como en la Antigüedad grecolatina-, donde su experiencia y conocimiento enriquecerían las decisiones de los diputados, ciudadanos con menor recorrido político.

Para Jorge Basadre Grohman, el carácter del proyecto de Constitución de Herrera era:

... un exponente de autoritarismo extremo que paradójicamente ostenta puntos de contacto con algunas de las tendencias aparecidas en el Derecho constitucional en el periodo intermedio entre las guerras mundiales: el robustecimiento del poder del Estado en desmedro del individuo y la representación corporativa ${ }^{19}$.

19 Jorge Basadre Grohman, Historia de la República del Perú (Santiago de Chile: Talleres de Cochrane, 2000, tomo IV), 890. 
Sin embargo, podemos notar que la tendencia fue robustecer al Estado desde la figura del presidente, frente a un Poder Legislativo que ya había conquistado la moción de censura y la interpelación como facultades suyas; como contraparte, Herrera sostuvo que cabía su disolución por el jefe del Ejecutivo. Estos planteamientos conjugaban el derecho y la ley con el ejercicio de la soberanía, premunida por el orden divino y garante contra todo tipo de violencia e inseguridad.

Estos dos aspectos tuvieron su efecto inmediato en el debate sobre la reinstauración de la pena de muerte. En 1858 se instaló el nuevo Congreso de la República, cuyo gran objetivo fue la reforma de la Constitución de 1856. Herrera dirigió la discusión bajo el argumento de que la abolición de la pena implicaba el premio para los facinerosos y malhechores, sobre todo en los momentos álgidos que había sufrido el país. En Herrera podemos observar una transición de sus postulados: abolicionista en sus inicios, pero terminando por considerar la pena de muerte una sanción necesaria para los homicidas, como instrumento que el Estado tenía en sus manos con el fin de preservar la sociedad.

En el año 1860, Bartolomé Herrera se convirtió en presidente del Congreso, y durante el tiempo que ejerció el cargo puso dedicación, disciplina y voluntad en el proyecto de Constitución de ese entonces. Esta actitud se corrobora con la apertura a la asistencia de ciudadanos a las sesiones abiertas del Legislativo. Nuestro ideólogo señalaba que la reforma de la Constitución debía basarse principalmente en dos temas: la religión y el Poder Legislativo. Con respecto a este último punto, mencionó las consecuencias que acarreaba el retiro de los diputados, pues perjudicaba el normal desarrollo del trabajo parlamentario al no contarse con el número de votos necesarios para la aprobación de las leyes.

Aspecto que era vital, más aún, si Herrera señalaba la necesidad de que las normas se aprueben con el voto calificado de los dos tercios de diputados hábiles durante las legislaturas ordinarias. Estos debates sirvieron también para reconsiderar el retorno de la jurisdicción eclesiástica, abolida en la Carta Magna anterior, así como la defensa del fuero militar. Las discusiones, sin embargo, se vieron al final trabadas, lo que causó la renuncia irrevocable de Herrera tanto al cargo como al Parlamento en 1860. Sus últimos años los dedicó a su labor pastoral y formativa en el seminario de San Jerónimo de Arequipa, donde falleció en 1864, legando a la posteridad su contribución a la consolidación de la democracia peruana. 


\section{Referencias}

Alzamora Valdez, Mario. El pensamiento político de Bartolomé Herrera. Lima: Mercurio Peruano 273, 1950.

Baquíjano y Carrillo, José. «Elogio al excelentísimo señor don Agustín de Jáuregui y Aldecoa...». Boletín del Museo Bolivariano 12 (1929).

Basadre Grohman, Jorge. Historia de la República del Perú. Santiago de Chile: Talleres de Cochrane, 2000, tomo IV.

Comisión del Sesquicentenario de la Independencia del Perú. Colección documental para la Independencia del Perú. Lima: Imprenta Colegio Militar Leoncio Prado, 1974, tomo I.

Comisión del Sesquicentenario de la Independencia del Perú. Colección documental para la Independencia del Perú, Epistolario de José de San Martín. Lima: Imprenta Colegio Militar Leoncio Prado, 1974, tomo XIII.

De La Puente, Carlos A. Ensayos y oraciones. Lima: Gráfica Americana, 1964.

Garavito Amézaga, Hugo. «Bartolomé Herrera: ¿un liberalismo autárquico?». En Bartolomé Herrera y su tiempo, compilado por Fernán Altuve-Febres Lores. Lima: Editorial Quinto Reino, 2010.

Gramsci, Antonio. La formación de intelectuales. México: Editorial Grijalbo, 1967.

Guerra, François Xavier. «Identidad e independencia». En imaginar la nación, editado por François Xavier Guerra y Mónica Quijada. México, 1996.

Herrera, Bartolomé. «Oración que en las exequias celebradas el día 4 de enero de 1842 en la iglesia Catedral de Lima por el alma de S. E. el Generalísimo Presidente de la República D. Agustín Gamarra, muerto gloriosamente en el campo de Incahue, pronunció el Dr. D. Bartolomé Herrera, Cura y Vicario de Lurín». En Escritos y discursos. Lima: Librería Francesa

Científica y Casa Editorial Rosay, 1929, tomo I.

Leguía, Jorge Guillermo. Hombres e ideas en el Perú. Santiago de Chile: Ediciones Ercilla, 1941.

López, Sinesio. «Intelectuales y políticos en el Perú del siglo XX». En Pensamiento político Peruano. Lima: Desco, 1968. 
Monteagudo, Bernardo. Memoria sobre los principios políticos que seguí en la administración del Perú y acontecimientos posteriores a mi separación. Santiago de Chile: Imprenta Nacional, 1823.

Pareja Paz Soldán, José. Historia de las constituciones nacionales. Lima: Gráfica Zenit, 1944.

Riva-Agüero y Osma, José de la. Carácter de la literatura del Perú independiente. Lima: Pontificia Universidad Católica del Perú, 1961.

Viscardo y Guzmán, Juan Pablo. Carta a los españoles americanos. Lima: Ministerio de Educación, 1959.

\section{Sobre el autor}

Doctor en Geografía e Historia por la Universidad Complutense de Madrid, abogado y licenciado en Historia por la Pontificia Universidad Católica del Perú (PUCP). Diploma de PosDoctor en Filosofía Política por la Universidad Privada Antenor Orrego. Profesor de Derecho, especializado en Historia del Derecho y Derecho Constitucional, en la Universidad de Lima y en la Universidad ESAN. Investigador del Instituto de Investigación Científica (IDIC) de la Universidad de Lima y del Instituto Riva-Agüero de la PUCP. 
